\title{
The antifungal mechanisms of potato glycoalkaloids against Fusarium solani
}

\author{
Jing $\mathrm{He}^{1}$, Tian-tian Duo ${ }^{1}$, Wei Chen ${ }^{1}$, and Xiao-yan Zhang ${ }^{1}$ \\ ${ }^{1}$ Gansu Agricultural University
}

August 23, 2020

\begin{abstract}
The antifungal mechanism of potato glycoalkaloids was studied using a sensitive species, Fusarium solani. The effects of potato glycoalkaloid extract on the ultrastructure, membrane permeability, and contents of reducing sugar, soluble sugar, soluble protein, and mycelial fat of F. solani were determined. Potato glycoalkaloids significantly affected F. solani mycelial morphology, resulting in bubbly mycelial cell walls, incomplete outer layer, discontinuous cell membrane, disorganized structures of mitochondria and other organelles, and visible leakage of cell contents. Investigation of material metabolism indicated that potato glycoalkaloids disrupted selective permeability of mycelial cell membranes; caused massive exudation of internal lipids, proteins, and carbohydrates; hindered hydrolysis of reducing sugar; affected nutrient absorption and utilization; and inhibited decomposition metabolism of mycelia. Thus, potato glycoalkaloids altered the morphology of fungal mycelia, destroyed cell membrane structure, increased mycelial cell membrane permeability, and caused cell contents leakage, resulting in effective inhibition of growth and metabolism of plant pathogenic fungi and so could decrease the occurrence of plant disease.
\end{abstract}

The antifungal mechanisms of potato glycoalkaloids against Fusarium solani Jing He ${ }^{1,2}$, Tian-tian Duo ${ }^{1}$, Wei Chen ${ }^{1}$, Xiao-yan Zhang ${ }^{1}$ ${ }^{1}$ College of Forestry, Gansu Agricultural University, Lanzhou 730070, China 2 Agronomy College, Gansu Agricultural University, Lanzhou 730070, China

\begin{abstract}
The antifungal mechanism of potato glycoalkaloids was studied using a sensitive species, Fusarium solani . The effects of potato glycoalkaloid extract on the ultrastructure, membrane permeability, and contents of reducing sugar, soluble sugar, soluble protein, and mycelial fat of $F$. solani were determined. Potato glycoalkaloids significantly affected $F$. solani mycelial morphology, resulting in bubbly mycelial cell walls, incomplete outer layer, discontinuous cell membrane, disorganized structures of mitochondria and other organelles, and visible leakage of cell contents. Investigation of material metabolism indicated that potato glycoalkaloids disrupted selective permeability of mycelial cell membranes; caused massive exudation of internal lipids, proteins, and carbohydrates; hindered hydrolysis of reducing sugar; affected nutrient absorption and utilization; and inhibited decomposition metabolism of mycelia. Thus, potato glycoalkaloids altered the morphology of fungal mycelia, destroyed cell membrane structure, increased mycelial cell membrane permeability, and caused cell contents leakage, resulting in effective inhibition of growth and metabolism of plant pathogenic fungi and so could decrease the occurrence of plant disease.
\end{abstract}

Keywords:Potato glycoalkaloids; Fusarium solani ; Antifungal mechanism 


\section{Introduction}

Plants produce more than 400,000 kinds of bioactive components, such as alkaloids, organic acids, flavonoids, phenols, and plant essential oils, most of which have anthelmintic, insecticidal, antifungal, or antibacterial activities (Yao et al., 2017). These bioactive compounds have a broad spectrum of target organisms, are safe for non-target organisms, and are characterized by low toxicity, low residue, easy degradation, and no target resistance (He et al., 2006; Yoon et al., 2013; Zhang et al., 2013). Plant bioactive components are a key research topic for controlling many plant diseases and developing new botanical pesticides, with prospects of wide exploitation and utilization ( $\mathrm{Li}$ et al., 2017; Tang et al., 2018). Potato glycoalkaloids are steroids produced as secondary metabolites by potatoes (Guo et al., 2017). The main components of potato glycoalkaloids are $\alpha$-solanine and $\alpha$-chaconine (Zhao et al., 2013), which represent more than $95 \%$ of the total glycoalkaloids (Kodamatani et al., 2005). Previous studies have shown that potato glycoalkaloids have a wide range of biological activities (Qiao, 2017) and can inhibit infection or growth of fungi, bacteria, viruses, and other plant pathogenic microorganisms, prevent insects from feeding or harming plants (Friedman, 2004; Liang et al., 2017), exert protective effects on plants, and possess important medicinal value (Zhao et al., 2013). Fewell et al. (1993) reported that $\alpha$-solanine and $\alpha$-chaconine in potatoes can inhibit the growth of fungi such as Alternaria brassicicola, Ascobolus crenulatus, Rhizoctonia solani, and Phoma medicaginis (Fewell and Roddick, 1993). Furthermore, Zhao et al. (2013) showed that potato glycoalkaloids have high inhibitory effects on Alternaria porriand Cercosporella brassicae, and Ombra et al. (2014) found that potato extract had antibacterial activity against Bacillus cereus, Escherichia coli, and Pseudomonas aeruginosaunder in vitro conditions.

Fusarium is one of the most important fungi in nature, and can survive in soil and plants during winter and summer, with wide distribution, diverse hosts, strong resistance, and rapid growth and reproduction (Du, 2017). Fusarium solani is one of the most common Fusarium spp., which infects the host vascular tissue, destroys its conducting tissue, and produces toxins that harm crops during growth, development, and metabolism. To date, F. solani is one of the most difficult plant pathogens to control in production, and can cause root diseases in various economic crops worldwide, such as white mulberry (Zhang, 2013), Chinese angelica (Zhao et al., 2012), walnut (Zheng et al., 2016), medlar (Chen et al., 2017), wild pepper (Li et al., 2016), and pear (Tang et al., 2017). Fusarium solani can also cause fruit rot (Ramdial and Rampersad, 2010) and deformity (Zhao et al., 2018), resulting in wilting and death of crops, affecting yield and quality, and producing huge economic losses. Currently, F. solani control depends on chemical fungicides such as carbendazim, mancozeb, thiram, cymoxanil-mancozeb, Xinjunan acetate, or pyrazole-kresoxim-methyl (Chen et al., 2017; Tang et al., 2017; Wang et al., 2014). However, long-term usage of chemical fungicides can result in pesticide residues, environmental pollution, and disease resistance, leading to a series of adverse effects (Yao et al., 2017). Therefore, developing alternatives for chemical fungicides using active substances in plants, such as botanical pesticides, is urgently needed.

Currently, studies on control of $F$. solani disease using plant bioactive compounds as well as the antifungal mechanism of these compounds are limited. Zhao et al. (2012) showed that the growth inhibitory rate of aqueous extracts of berberine (root), licorice (root), and burdock (root) at a concentration of $0.2 \mathrm{~g}[?] \mathrm{mL}^{-1}$ on $F$. solani causing root rot inAngelica sinensis exceeded $50 \%$, also inhibiting spore germination to some extent. Zhang et al. (2013) demonstrated that the volatiles and extracts of onions, scallions, garlics, and leeks had obvious inhibitory effects on F. solani . Furthermore, Zhao et al. (2009) revealed that the water extracts of nine plants - including wheat (whole plant) and corn (root, stem, and leaf) - had a high inhibitory effect on F. solani growth.

Potato glycoalkaloid extract has been noted to have some inhibitory effect on three economic forest pathogenic fungi: F. solani ,Capnodium leaophilum, and Marssonina juglandis . Notably, the inhibitory effect on $F$. solani was the strongest (Duo et al., 2017). Therefore, in the present study, the effects of potato glycoalkaloid extract on the ultrastructure, cell membrane permeability, and contents of reducing sugar, soluble sugar, soluble protein, and mycelial fat of $F$. solani were examined, and the inhibition mechanism was preliminarily determined. The results could provide a theoretical basis for prevention and control of economic forest 
diseases as well as for the development and utilization of plant-derived fungicides.

\section{Materials and methods}

\subsection{Materials}

The commercially available potato variety Qingshu 9 was purchased after 1 month of harvest. The fresh potato samples were washed and dried in sunlight for several weeks to turn the potato skin green and allow germination. Subsequently, the green potato skin and buds were dried in a vacuum blast drying oven and pulverized into a powder using a plant pulverizer through an 80 -mesh sieve and stored at $0-4^{\circ} \mathrm{C}$ until further use.

The test strain of F. solani was isolated from Lycium barbarum root rot in Gansu Province, China (Fang, 1998), and its pathogenicity was confirmed based on Koch's postulates. After identification, the strain was stored at $0-4^{\circ} \mathrm{C}$ until further use. Potato dextrose broth (PDB) and potato dextrose agar (PDA) were employed for fungal cultivation. The PDB comprised $200 \mathrm{~g}$ of peeled potato, $20 \mathrm{~g}$ of glucose, and $1000 \mathrm{~mL}$ of distilled water (neutral $\mathrm{pH}$ ). The PDA was prepared by adding 17-20 g of agar to the constituents of PDB. All reagents used were of domestic analytical grade and purchased from Gansu Zhongrui Chemical Co. Ltd., China.

\subsection{Methods}

\subsubsection{Extraction of potato glycoalkaloids}

Potato glycoalkaloids were extracted using an acetic acid extraction-ammonia precipitation method with slight modifications (Bo et al., 2012). In brief, $100 \mathrm{~g}$ of the potato sample was mixed with $400 \mathrm{~mL}$ of $5 \%$ acetic acid, stirred for 60 min (JB-1 magnetic stirrer, Shanghai Leici Xinjing Instrument Co. Ltd., China), and filtered (SHZ-D III circulating water vacuum pump, Gongyi Yuhua Instrument Co. Ltd., China). The residue was extracted twice with $200 \mathrm{~mL}$ of $5 \%$ acetic acid, and the filtrate was combined and its $\mathrm{pH}$ adjusted to 11 with ammonia. After extracting three times with $200 \mathrm{~mL}$ of water-saturated n-butanol, the extracts were combined and dried on a rotary evaporator (RE-3000, Shanghai Yarong Biochemical Instrument Factory, China), and the residue mixed with $20 \mathrm{~mL}$ of methanol to obtain total glycoalkaloid extract. The mass concentration of the glycoalkaloid extract was $5 \mathrm{~g}[?] \mathrm{mL}^{-1}$.

\subsubsection{Effect of potato glycoalkaloids on $F$. solaniultrastructure}

The F. solani was inoculated onto PDA at a concentration of $0.3036 \mathrm{~g}[?] \mathrm{mL}^{-1}\left(\mathrm{EC}_{50}\right)$, along with $2 \mathrm{~g}[?] \mathrm{mL}^{-1}$ potato glycoalkaloid extract, and incubated at $25 \mathrm{degC}$ for $48 \mathrm{~h}$. Subsequently, sterile filter paper strips $(0.7$ $\mathrm{cm} \times 5 \mathrm{~cm}$ ) were placed around the colony (covering an area of $5 \mathrm{~cm} \mathrm{x} 5 \mathrm{~cm}$ ) and incubated at 25degC. After $72 \mathrm{~h}$, the edge of the colony was sampled. The collected sample was fixed by double fixation with glutaraldehyde and citric acid (Zeng, 2012), and observed and photographed under a transmission electron microscope (JEM2000EX; JEOL, Japan).

\subsubsection{Effect of potato glycoalkaloids on F. solani cell membrane permeability}

The mycelia of $F$. solani were cultured in PDB for 4 days and washed four times with ultrapure sterile water. Then, the washed mycelia were freeze-dried to a constant weight (Labconco freeze drier, USA) and $1 \mathrm{~g}$ of the mycelia was transferred into $5 \mathrm{~mL}$ of potato glycoalkaloid $\left(\mathrm{EC}_{50}\right)$ extract and incubated at $25 \mathrm{degC}$ under constant shaking at $120 \mathrm{r}[?] \mathrm{min}^{-1}$. Subsequently, conductivity of the culture broth was measured (DDB303A digital conductivity meter, Shanghai Yidian Scientific Instrument Co. Ltd., China) hourly during 0-9 $\mathrm{h}$. Finally, the culture broth was boiled in a water bath (HH-S6 digital display thermostat water bath, Jintan Medical Instrument Factory, China) for $10 \mathrm{~min}$ and conductivity was determined. The experiment 
was repeated thrice, with sterile water and methanol as controls, The permeability of cell membrane was expressed as relative permeability $(\%)=$ (relative time conductivity value - initial conductivity value) $/($ kill conductivity value - initial conductivity value) x 100\% (Shen, 2014).

\subsubsection{Effect of potato glycoalkaloids on soluble mycoprotein in $F$. solani}

The effect of potato glycoalkaloids on soluble mycoprotein was determined by Coomassie Brilliant Blue G-250 staining (Song, 2010). In brief, mycelia of F. solani were cultured in PDB for 4 days, and washed four times with ultrapure sterile water. Then, the washed mycelia were freeze-dried (Labconco) to a constant weight and $1 \mathrm{~g}$ of the mycelia was added to $5 \mathrm{~mL}$ of potato glycoalkaloid $\left(\mathrm{EC}_{50}\right)$ extract, and sampled at $0,2,4$, 6 , and $8 \mathrm{~h}$. The collected samples were centrifuged (D-37520 centrifuge, Heraeus Biofuge, Germany), and the absorbance of samples was recorded at $595 \mathrm{~nm}$ (Jenway $6505 \mathrm{UV} /$ Vis UV Spectrophotometer; Gaonan Instrument (Shenzhen) Co. Ltd. China). The protein concentration was calculated according to the protein standard curve, and the experiment was repeated thrice, with sterile water and methanol as controls.

\subsubsection{Effect of potato glycoalkaloids on soluble sugar in $F$. solani}

The effect of potato glycoalkaloids on soluble sugar in F. solaniwas determined by anthrone colorimetry (Yao et al., 1992). In brief, F. solani mycelia were cultured in PDB for 4 days, and then washed four times with ultrapure sterile water. Then, the washed mycelia were freeze-dried (Labconco) to a constant weight and $1 \mathrm{~g}$ of mycelia mixed with $5 \mathrm{~mL}$ of potato glycoalkaloid $\left(\mathrm{EC}_{50}\right)$ extract, and sampled at $0,1,2,4,6,8$, 10, and $12 \mathrm{~h}$. Subsequently, collected samples were subjected to centrifugation (6000 rpm; 5 min), heated with anthrone reagent, and cooled to room temperature, and the absorbance of the samples measured at 620 $\mathrm{nm}$. The soluble sugar content was calculated according to the glucose standard curve, and the experiment was repeated thrice, with sterile water and methanol as controls.

\subsubsection{Effect of potato glycoalkaloids on reducing sugar in $F$. solani}

The effect of potato glycoalkaloids on reducing sugar in $F$. solani was determined by 3,5-dinitrosalicylic acid (DNS) method (Chen, 2002). In brief, F. solani mycelia were cultured in PDB for 4 days, and washed four times with ultrapure sterile water. Then, the washed mycelia were freeze-dried (Labconco) to a constant weight and $1 \mathrm{~g}$ of mycelia was added to $5 \mathrm{~mL}$ of potato glycoalkaloid $\left(\mathrm{EC}_{50}\right)$ extract, and sampled hourly during $0-8 \mathrm{~h}$. Subsequently, $1 \mathrm{~mL}$ of the collected samples was respectively subjected to centrifugation (6000 $\mathrm{rpm} ; 5 \mathrm{~min}$ ), and $0.5 \mathrm{~mL}$ of the supernatant was mixed with $1.5 \mathrm{~mL}$ of distilled water and $1.5 \mathrm{~mL}$ of DNS reagent to determine the absorbance at $520 \mathrm{~nm}$. The reducing sugar content was calculated according to the standard curve, and the experiment was repeated thrice, with sterile water and methanol as controls.

\subsubsection{Effect of potato glycoalkaloids on fat content in $F$. solani}

The oil weight method was employed for sample processing and fat content determination (Li, 1987). The F. solani mycelia were cultured in PDB for 4 days and washed four times with ultrapure sterile water. Then, the washed mycelia were freeze-dried (Labconco) to a constant weight and $1 \mathrm{~g}$ of the mycelia was added to $5 \mathrm{~mL}$ of potato glycoalkaloid $\left(\mathrm{EC}_{50}\right)$ extract, and sampled at 24,48 , and $72 \mathrm{~h}$. Subsequently, the collected samples were filtered (SHZ-D III circulating water vacuum pump) and rinsed with redistilled water four times; the obtained wet hyphae were dried at $60-80 \operatorname{degC}$ for $4 \mathrm{~h}$, smashed with a mortar and pestle, and filtered through a mesh sieve to obtain dried powder. The procedure was repeated thrice, and sterile water and methanol were used as controls. For fat content determination, the Soxhlet extractor was cleaned, heated in a blast drying oven at $105 \mathrm{deg} \mathrm{C}$ for $20 \mathrm{~min}$, cooled to room temperature, and weighed $(\mathrm{m})$. Then, 12-cm quantitative filter paper was weighed $\left(\mathrm{m}_{1}\right)$ and made into a bucket, and $2 \mathrm{~g}$ of the dried sample powder were added to the filter paper bucket and weighed $\left(\mathrm{m}_{2}\right)$. The difference between the two masses indicated the quality of the dried sample powder $\left(m_{3}=m_{2}-m_{1}\right)$. Subsequently, the dried sample was soaked in petroleum ether overnight, and heated in a thermostat water bath for $65 \mathrm{degC}$. Reflux extraction was performed for $12 \mathrm{~h}$ using a Soxhlet fat extractor, and then the extract was heated at 100degC for $8 \mathrm{~h}$, 
cooled to room temperature, and weighed (m'). Crude fat was calculated as follows: crude fat $(\%)=\left(\mathrm{m}^{\prime}\right.$ $\mathrm{m}) /\left(\mathrm{m}_{2}-\mathrm{m}_{1}\right) \times 100 \%$.

\subsection{Statistical analysis}

All data were analyzed using Excel 2007. The variance was examined using SPSS 19.0 and the difference investigated by employing Duncan's new complex range method (Zhou et al., 2014).

\section{Results}

\subsection{Effect of potato glycoalkaloids on $F$. solaniultrastructure}

The controls without potato glycoalkaloid treatment presented thin and uniform cell walls, complete structure, hyphae surrounded by a continuous outer layer, intact internal tissue structure, no extravasation of cell contents, normal development, and clearly visible vacuoles, mitochondria, and other organelles (Fig. 1A). However, after treatment with $\mathrm{EC}_{50}$ potato glycoalkaloids, the fungal cell walls became thinner and irregular, cell internal structure was disrupted, and some membrane structures were incomplete (Fig. 1B). Furthermore, after treatment with $2 \mathrm{~g}^{*} \mathrm{~mL}^{-1}$ potato glycoalkaloids, cell walls of mycelia had a bubble shape, outer layer components were altered, cell wall structure was incomplete, the outer cell membrane was discontinuous, structure of mitochondria and other organelles was not obvious, and extracellular inclusions were exuded (Fig. 1C). In contrast, following treatment with methanol, the cell wall structure was clear, mitochondria and ribosomes were clearly visible, and the vacuolar structure was intact, indicating that methanol did not affect antibacterial activity of potato glycoalkaloids (Fig. 1D). These findings indicated that potato glycoalkaloids destroyed the cell surface morphology of F. solani, severely damaging the cytoplasm, mitochondria, and other organelles, as well as increasing the cell membrane permeability and so causing leakage of cell contents.

\subsection{Effect of potato glycoalkaloids on F. solani cell membrane permeability}

Figure 2 shows the effects of potato glycoalkaloids on the cell membrane permeability of $F$. solani . The relative cell membrane permeability increased with time in both the control and treatment groups. However, the relative cell membrane permeability was significantly higher for the treatment compared with the control group. In both the control and treatment groups, the relative cell membrane permeability rapidly increased during 1-4 h, with a greater increase for the treatment than the control group. After $4 \mathrm{~h}$, the difference in relative cell membrane permeability quickly broadened between the two groups, indicating that the $F$. solani cell membrane damage caused by potato glycoalkaloids at $\mathrm{EC}_{50}$ concentration intensified at $4 \mathrm{~h}$. Subsequently, the relative cell membrane permeability of the control group gradually decreased during 4-9 $\mathrm{h}$, whereas that of the treatment group increased by $25.2 \%$ at $9 \mathrm{~h}$, and remained stable at 8 and $9 \mathrm{~h}$.

\subsection{Effect of potato glycoalkaloids on soluble protein in $F$. solani}

The soluble protein leakage in the treatment group exhibited an upward trend with time, which significantly differed from that in the control group (Fig. 3). During 0-6 h, soluble protein leakage in the treatment group increased from 66.50 to $169.51 \mu \mathrm{g}[?] \mathrm{mL}^{-1}$, which was much higher than that in the control group. However, during $6-24 \mathrm{~h}$, the soluble protein leakage in the treatment group gradually decreased with time, possibly due to consumption of soluble proteins by newly formed $F$. solani cells for growth. After $24 \mathrm{~h}$, the soluble protein leakage in the treatment and control groups gradually increased and stabilized. 


\subsection{Effect of potato glycoalkaloids on soluble sugar in $F$. solani}

Soluble sugar leakage in the treatment group significantly differed from that in the control with time (Fig. 4). During 0-24 h, soluble sugar leakage in the treatment group increased from 117.4 to $132.5 \mu \mathrm{g}[?] \mathrm{mL}^{-1}$, which was much higher than that in the control group. However, after $24 \mathrm{~h}$, leakage in the treatment group decreased with time owing to consumption of soluble sugar in the extracellular fluid by newly formed $F$. solani cells for growth.

\subsection{Effect of potato glycoalkaloids on reducing sugar content in $F$. solani}

The reducing sugar content in the extracellular fluid significantly differed between the treatment and control group with time (Fig. 5). In both groups, the reducing sugar content in the extracellular fluid sharply decreased during $0-2 \mathrm{~h}$, but gradually reduced during $2-72 \mathrm{~h}$, indicating that potato glycoalkaloids significantly decreased the absorption and utilization of reducing sugar by $F$. solani.

\subsection{Effect of potato glycoalkaloids on fat content in F. solani}

The fat content in the extracellular fluid of both the treatment and control groups increased during 0-48 $\mathrm{h}$, with significantly higher fat leakage for the treatment compared with the control group (Fig. 6). The fat content in the extracellular fluid of the treatment group increased by $54.20 \%$ and $52.07 \%$, compared with sterile water and methanol control groups at $48 \mathrm{~h}$, respectively, indicating that potato glycoalkaloids damaged the cell structure and caused fat content leakage from $F$. solani plasma membrane. However, after $48 \mathrm{~h}$, fat content in the extracellular fluid of both treatment and control groups showed a downward trend, possibly resulting from a weakening effect of potato glycoalkaloids or a self-remediation mechanism of $F$. solani .

\section{Discussion and conclusions}

Plant bioactive substances mainly target the cell membrane of fungi by altering membrane stability and causing damage to the membrane structure and extravasation of inclusions, ultimately resulting in fungicidal or fungistatic effect (Zhou et al., 2014). Previous studies have shown that glycoalkaloids predominantly combine with sterols in the fungal cell membrane, forming a complex that destroys membrane integrity and causes loss of normal membrane function (Sun, 2014). In the present study, transmission electron microscopy showed that $F$. solani morphology was distorted after potato glycoalkaloid treatment, and that some cell walls were blurred or even lost. Additionally, structure of the cell and vacuolar membranes was destroyed and the organelles distorted. These observations indicated that potato glycoalkaloids can affect the surface morphology of F. solani, leading to incomplete membrane structure and causing serious damage to cytoplasm and mitochondria, consistent with the effect of pyrolin on Monilinia fructicola (Wu et al., 2009), ethyl acetate extract of amaranth on Xanthomonas citri(Liao et al., 2017), and water-soluble chitosan on the ultrastructure ofFusarium (Jia et al., 2016).

Electrical conductivity can indirectly reflect cell membrane permeability, and a higher electrical conductivity of a culture broth signifies enhanced electrolyte leakage and increased damage to cell membranes (Shang, 2017). Peng et al. (2017) showed that extract ofCynanchum atratum could enhance the cell membrane permeability of Italian Penicillium mycelium, while Zhang et al. (2008) revealed that the extract of Xanthium sibiricum induced changes in membrane permeability of Botrytis cinerea, resulting in increased conductivity of the culture broth. Furthermore, Liu et al. (2018) found that the total saponins and total ginsenoside from ginseng stem and leaf can induce changes in the permeability of the mycelium membrane of Fusarium pediculae and F. solani, respectively, leading to increased conductivity of the culture broth. Liu et al. (2018) showed that limonene can increase the permeability of $P$. aeruginosa cell membrane and destroy its cell morphology and integrity, thus effectively inhibiting its growth. Similarly, in the present study, the cell 
membrane permeability of $F$. solani increased after treatment with potato glycoalkaloids, and transmission electron microscopy revealed leakage of intracellular contents and destruction of cell membrane structure. These results showed that $F$. solani cell membrane and integrity were destroyed by potato glycoalkaloids, which directly affected the physiological functions of the cell membrane, such as exchange of intracellular and extracellular substances and regulation of cell growth, leading to disturbance in fungal metabolism.

It must be noted that plant bioactive compounds also affect the morphology and structure of fungal mycelia, causing deformity, kinking, swelling, and lysis. As a result, the mycelial soluble protein and soluble sugar can leak into the culture medium (Fan et al., 2015; Zhang et al., 2016; Zhou et al., 2011). In fungi, soluble protein mainly comprises various enzymes involved in metabolism. During growth, the fungi secrete proteins that penetrate the cell membrane into the thallus fluid through osmosis; thus, changes in the content of these proteins reflect alteration in the total cellular metabolism (Liu et al., 2016). Sugar catabolism provides the energy needed for fungal growth, and inhibition of the absorption and utilization of sugar could lead to lack of energy required by the fungi, affecting growth and propagation of the thallus (Liu et al., 2016). The total lipid content in the fungal cell membrane affects cell membrane fluidity, and a decrease in the total lipid content may lead to a reduction in cell membrane fluidity (Shang, 2017). Thus, one approach to achieve fungicidal or fungistatic effect is to inhibit fungal metabolism (Zhou et al., 2014). In the present study, the contents of total sugar, protein, and fat in $F$. solani initially increased and then decreased with time after treatment with potato glycoalkaloids. However, the content of reducing sugar decreased in $F$. solani treated with potato glycoalkaloids, but significantly increased in control cells without glycoalkaloid treatment. Similar findings were also reported by Wu (2008), who showed that the contents of total sugar, reducing sugar, protein, and fat in $B$. cinerea treated with propamidine were significantly higher than those in control B. cinerea without treatment, indicating that plant bioactive compounds inhibited catabolism in fungi. Biological catabolic systems are complex, and disturbance in a certain catabolic link can obstruct the entire catabolic process, threatening life of the organism. However, self-remedial mechanisms can overcome the blocked metabolic processes to continue life activities (Zeng, 2012). Therefore, it is possible that selfremedial mechanisms of $F$. solani allowed the fungal cells to thrive after potato glycoalkaloid treatment, resulting in an initial increase and subsequent decrease in contents of total sugar, protein, and fat with treatment duration.

Furthermore, potato glycoalkaloids significantly affected the morphological structure of $F$. solani . Treatment with potato glycoalkaloids resulted in bubbly and undulated mycelial cell walls, incomplete outer structure, discontinuous cell membrane, disordered structure of mitochondria and other organelles, and visible extracellular contents. The material metabolism analysis demonstrated that potato glycoalkaloids destroyed the selective permeability of fungal cell membranes and causing extravasation of large quantities of internal lipids, proteins, and sugars. This hindered the hydrolysis of reducing sugars, affecting the absorption and utilization of nutrients, and ultimately inhibiting catabolism in fungi. However, knowledge of the specific antifungal mechanism of potato glycoalkaloids is limited. Therefore, further research on the effects of potato glycoalkaloids on fungal respiratory metabolism (e.g. related enzymes activities) and energy metabolism (e.g. inhibition of electron transport and oxidative phosphorylation, and information expression of nucleic acids and other molecular substances) is necessary for a better understanding of the antifungal mechanism of these compounds and for acquiring comprehensive and systematic theoretical support for the development and utilization of botanical pesticides.

\section{Acknowledgements}

The work was supported by grants from the Natural Science Foundation of Gansu Province (17JR5RA146), Special Funds for Discipline Construction of Gansu Agricultural University (GAU-XKJS-2018-096), and Supporting Funds for Youth Mentor of Gansu Agricultural University (GAU-QDFC-2018-07) and Postdoctoral Research Projects (2015GSZYZZ002).

We thank International Science Editing (http://www.internationalscienceediting. com) for editing this manuscript. 
The named authors have no conflict of interest, financial or otherwise.

\section{References}

Bo, L. L., Sun, X. Y., Lin, H. Dai, M. J., Niu, J. P., Zhang, J. W., Wang, D., 2012. Extraction of glycoalkaloids from potatoes. Anhui Agricultural Science. 40 (3),1448, 1491.

Chen, W., He, J., Duo, T. T., Xue, R. J., Xu, H. J., Yang, H. J., 2017. Laboratory toxicity test of Several Fungicides against root rot pathogens of Lycium barbarum. Journal of Gansu Agricultural University. $52(01), 109-113$.

Chen, Y. Q.,2002. Methods and techniques of biochemistry experiment. Beijing: Science Press.

Du, B., 2017. Classification and Research Status of Fusarium. Journal of Taiyuan University (Natural Science Edition). 35(04),68-70.

Duo, T. T., He, J., Chen, W., Zhang, J. W., Feng, S. H., Ma, H. Y., Du, J., 2017. Antibacterial activity of potato glycoalkaloids and their effects on cell membrane permeability. Journal of Gansu Agricultural University. 52 (05),50-54.

Fan, M. C., Sun, Y. J., Li, W. X., Kou, X. K., 2015. Screening and mechanism study of antibacterial effect of natural plant extracts. Journal of Chinese Institute of Food Science and Technology. 15(09),180-185.

Fang, Z. D.,1998. Research method of plant disease(Third Edition). Beijing: China Agriculture Press.

Fewell, A. M., Roddick, J. G., 1993. Interactive antifungal activity of the glycoalkaloids $\alpha$-solanine and $\alpha$-chaconine. Phytochemistry. 33(2),323-328.

Friedman, M., 2004. Analysis of biologically active compounds in potatoes (Solanum tuberosum ), tomatoes (Lycopersicon esculentum), and jimson weed(Datura stramonium ) seeds. Journal of Chromatography A. 1054,143-155.

Guo, H. X., Zhang, J. J., An, R., Qiao, Y., Shi, W. H., Shi, J., Zhang, J. W., 2017. Study on the regulation of glycosidic alkaloid synthesis in green tissues of potato aboveground parts. Journal of Horticulture. 44(06),1105-1115.

He, J., Ma, Z. Q., Zhang, X., 2006. An overview of botanical pesticides. Journal of Northwest A\& F University. 34 (9),79-85.

Jia, R. X., Qiu, M., Huang, J. Y., Zhou, Y., 2016. Antimicrobial mechanism of chitosan and its derivatives against Fusarium . Chinese Journal of Food. 16 (11),70-75.

Kodamatani, H., Saito, K., Niina, N., Yamazaki, S., Tanaka, Y., 2005. Simple and sensitive for determination of glycoalkaloids in potato tubers by high-performance liquid chromatography with chemiluminescence detection. Journal of Chromatography A. 1100,26-31.

Li, C., 1987. Principles and techniques of food analysis (The first edition). Beijing: Science and Technology Literature Press.

Li, C. B.,2017. Bioactivity of ten plant extracts against pathogenic bacteria in tea leaves. Wuhan: Huazhong Agricultural University.

Li, S. J., Zhu, T. H., Cen, T. M. Han, S., 2016. Screening, identification, colonization and control effect of Bacillus spp. Against root rot of Zanthoxylum bungeanum. Journal of Northwest University of Agriculture and Forestry Science and Technology(Natural Science Edition). 44(04),114-122.

Liang, K. H., Lu, L. G., Zhu, D. Z., Zhu, H., 2017. Research progress of potato glycoalkaloids. Food research and development. 38(21),195-199. 
Liao S. L., Yin, W., Liao, X. L., Zhang Y., 2017. Study on the inhibition and mechanism of ethyl acetate extract from Amaranth on Citrus canker. Journal of Hunan Agricultural University (Natural Science Edition). 43(05),544-550.

Liu, F. F., Zhang, A. H., Lei, F. J., Xu, Y. H., Zhang, L. X., 2018. Inhibitory effect of total saponins from ginseng stem and leaf onFusarium oxysporum and its bacteriostatic mechanism. Journal of Jilin Agricultural University. 40 (01),85-91.

Liu, J. Y., Zhao, Q. Q., Zhang, Z. Y., Den, H., Qi, N., Li, H., 2016. Preliminary study on the antibacterial activity and mechanism of sterols in seed oil of Xanthoceras sorbifolia L. Chinese Oil. 41(10),29-33.

Liu, X., Wang, J. N., Chen, W. X., Chen, R. H., Zhang, G. F., 2018. The antibacterial activity and mechanism of limonene againstPseudomonas aeruginosa . Food Industry Science and Technology. 39(07),159.

Neve, O. M., Florinda, F., Tiziana, G., Federica, C., Autilia, C., 2014. In vitro antioxidant, antimicrobial and anti-proliferative activities of purple potato extracts (Solanum tuberosum cv Vitelotte noire) following simulated gastro-intestinal digestion. Natural Product Research. 14(1),1-5.

Peng, X., Chen, Y. H., Chen, J. Y., 2017. Study on the bacteriostatic mechanism of Italian penicillium and the control effect of umbilical cord orange-penicillium by bai wei extract. Journal Chineseof Plant Pathology. $47(03), 398-405$.

Qiao, Y., 2017. Identification and functional analysis of miRNAs induced by photoinduced glucoside alkaloid metabolism in potato. Lanzhou: Gansu Agricultural University.

Ramdial, H A., Rampersad, S.N., 2010. First report of Fusarium solani causing fruit rot of sweet pepper in Trinidad. Plant Disease. 94(11),1375.

Shang, C. Y.,2017. Study on the antibacterial mechanism of $\beta$-pinene onPenicillium citrinum . Wuhan:Huazhong Agricultural University.

Shen, Y., 2014. Study on the screening and identification of endophytic actinomycetes from Maize and the mechanism of inhibition of Maize. Heilongjiang: Northeast Agricultural University.

Song, L., 2010. Inhibition and mechanism of BIT against Botrytis cinerea . Xi'an: Northwest University.

Sun, P. Z., 2014. Antimicrobial activity of potato alpha-solanine against Botrytis cinerea in vitro. Hohhot: Inner Mongolia Agricultural University.

Tang, X. H., Zhong, L.Y., Tang, T., Li, W. F., Li, X., Jiang, L., Zhao, G., Zhao, J. L., 2018. Inhibition of extracts from six kinds of perfume plants on Rhizoctonia solani of Buckwheat. Journal of Jiangxi Agricultural University. 40(01),89-95.

Tang, X. M., Lin, T. Y., Zhou, S. S., Li, G. F., Liu, P., Ye, Z. F., Wu, Z. Y., Wang, D. S., Zhu, L. W., 2017. Isolation and identification of pathogenic bacteria of pear root rot and screening of effective control agents. Journal of Nanjing Agricultural University40 (01),76-83.

Wang, Y. X., Xu, Y. K., Li, Z. M., 2014. Selection of 8 fungicides for main pathogenic bacteria of acanthopanax senticosus. Jilin Agriculture. (24),12.

Wu, F. L., 2008. Preliminary study on the antibacterial mechanism of propane oxime against Botrytis cinerea . Northwest A\&F University.

Wu, Z. Y., Wang, Y., Ai, Q. J., 2009. Inhibitory effect of pyrolysin on peach brown rot pathogen and its bacteriostatic mechanism. Chinese Agricultural Sciences. 42(08),2784-2792.

Yao, H. W., Ge, K. K., Pan, J. L., Liu, W. L., Ma, L., 2017. Screening of antibacterial activity of extracts from 29 plants such asSyringa . Journal of Northeast Forestry University. 45 (10),35-39. 
Yao, L. H., Xu, Q., 1992. Simplified study on the determination of total sugar content in food by anthrone colorimetry. Food industry (3),40-42.

Yoon, M. Y., Cha, B., Kim, J. C., 2013 Recent trends in studies on botanical fungicides in agriculture. Plant Pathology Journal. 29(1),1-9.

Zeng, R., 2012 Study on the antibacterial active components, antibacterial mechanism and the effect on citrus preservation and preservation of Impatiens balsamina L. Jiangxi: Nanchang University.

Zhang, L.,2013. The Application of spss19.0(Chinese version) in biostatistics(The third edition). Xiamen: Xiamen University Press.

Zhang, W., Liao, J. J., Zhu, G. L., Zhang, H., Duan, X. L., Zhu, S. S., Yang, M., 2013. Study on the inhibitory activity of 8 plant volatiles and extracts against root rot on Panax notoginseng. Chinese Agricultural Science Bulletin. 29(30),197-201.

Zhang, X., Wu, Z. F., Li, W., Ma, Z. Q., Feng, J. T., 2013. New progress in the development and application of botanical pesticides-Introduction to special biological activities. Pesticide Science and Management. 34 (4),24-31.

Zhang, X. H., He, J., Shen, H. M., 2008. Inhibitory effect of Xanthium sibiricum extract against Botrytis cinerea and its bacteriostatic mechanism. Journal of Grass Industry. (03),99-104.

Zhang, X. M., Xue, Q. L., Xiao, R., Zhao, L. Z., Lin, Q., Hu Y. J., 2016. Bacteriostatic mechanism of extracts from mistletoe against Staphylococcus aureus . Modern Food Science and Technology. 32 (01),82-88.

Zhang, Y. D., 2013. Pathogenic mechanism of mulberry root rot and screening of antagonistic bacteria. Zhenjiang:Jiangsu University of science and technology.

Zhao, Q. F., Liu, L., Li, Q. X., Li, H. Y., 2012. Preliminary screening of the inhibitory activity of 15 kinds of plant water extracts on root rot of Angelica sinensis. Journal of Northwest Normal University (Natural Science Edition). 48 (02),66-69,85.

Zhao, Q. F., Zhao, P. Q., Guo, P. H., Li, Q. X., Han, J., 2009. Preliminary Study on the inhibitory activity of water extracts from 17 plants on the root rot fungus of astragalus membranaceus. Journal of Northwest University of Agriculture and Forestry Science and Technology (Natural Science Edition). 37(03),163-167.

Zhao, X. S., Li, S. Y., He, D. J., Wang, J., 2013. Study on the structure-activity relationship of potato glycoalkaloids against fungal activity. Food Industry Science and Technology. 34 (6),159-163.

Zhao, Y. L., Wang, W., Pei, T. T., Tao, G., 2018.. Isolation and identification of the pathogen of mango malformation in Guizhou. Southwest China Journal of Agricultural Sciences. 31(03),494-499.

Zheng, L., Zhang, J., Ma, W. J. Pen, Y., Zhu, T. H., 2016. Effects ofFusarium solani on physiological indexes of resistance of different varieties of walnut. Guangxi Plants. 36(06),651-657.

Zhou, L., Yun, B. Y., Wang, Y. J., Xie, M. J., 2011. Antimicrobial mechanism of emodin against Staphylococcus aureus . Chinese Journal of Biochemistry and Molecular Biology. 27(12), 1156-1160.

Zhou, M. J., Wan, C. P., Chen, J. Y., 2014. Screening of high-efficiency antimicrobial agents of Chinese herbal medicine against Citrus green mold and their antimicrobial mechanism. Modern food science and technology. 30(03),144-149,75.

\section{Hosted file}

Figures.doc available at https://authorea.com/users/352611/articles/476781-the-antifungalmechanisms-of-potato-glycoalkaloids-against-fusarium-solani 